\title{
Live streaming em tempos pandêmicos: práticas informacionais realizadas por profissionais da Ciência da Informação
}

\section{Live streaming in pandemic times: informational practices performed by Information Science professionals}

\author{
Patrícia Valerim ${ }^{1}$, Rodrigo Silva Caxias de Sousa ${ }^{2}$ \\ ${ }^{1}$ Universidade Federal do Rio Grande do Sul (UFRGS), Porto Alegre, RS, Brasil. ORCID: http://orcid.org/0000-0002-1119-247X \\ 2 Universidade Federal do Rio Grande do Sul (UFRGS), Porto Alegre, RS, Brasil. ORCID: http://orcid.org/0000-0001-6872-4054
}

Autor para correspondência/Mail to: Rodrigo Silva Caxias de Sousa, rodrigo.caxias@ufrgs.br

Recebido/Submitted: 7 de agosto de 2020; Aceito/Approved: 29 de outubro de 2020

Copyright (c) 2020 Valerim \& Souza. Todo o conteúdo da Revista (incluindo-se instruções, política editorial e modelos) está sob uma licença Creative Commons Atribuição-NãoComercial-Compartilhalgual 3.0 Não Adaptada. Ao serem publicados por esta Revista, os artigos são de livre uso em ambientes educacionais, de pesquisa e não comerciais, com atribuição de autoria obrigatória. Mais informações em http://revistas.ufpr.br/atoz/about/submissions\#copyrightNotice.

\begin{abstract}
Resumo
Introdução: Analisa as lives realizadas por integrantes da comunidade da Ciência da Informação em meio à pandemia de covid-19, assumidas teoricamente como prática informacional que tem o objetivo de disseminar informações na web. Método: Adota uma abordagem exploratóriadescritiva e mista (quali-quantitativa), tendo como procedimento a observação assistemática na web e a análise de conteúdo relacionada às 74 lives realizadas por dois perfis do Instagram. Resultados: Confirma que os propósitos de prática informacional proposta pelos perfis selecionados. Infere que as temáticas abordam questões profissionais e acadêmicas, de tal forma que emergiram 11 categorias temáticas. Identifica a ampliação das audiências e a dispersão geográfica em relação à origem dos participantes. Conclusões: A caracterização das lives e dos convidados para apresentação de conteúdo demonstram que as práticas informacionais se pautam no conceito de disseminação de informações, o que pode ser identificado a partir das categorias propostas. As discussões levantadas também apontam a necessidade de que análises posteriores na Ciência da Informação possam ampliar interpretações acerca do objeto investigado.
\end{abstract}

Palavras-chave: lives; Pandemia; Práticas informacionais; Disseminação da Informação; Ciência da Informação

\begin{abstract}
Introduction: The study analyzes the live transmission carried out by members of the Information Science community during a covid-19 pandemic, assuming it theoretically as an informational practice that aims to disseminate information on the web. Method: it adopts an exploratory-descriptive, mixed (qualitative-quantitative) approach, with an unstructured observation procedure on the web and content analysis referring to 74 live streaming made by two Instagram profiles. The description allows us to confirm the purposes of the informational practice proposed by the selected Instagram profiles. Results: It infers that the themes address professional and academic issues so that 11 thematic categories emerged. It identifies an expansion of audiences and geographical dispersion regarding the origin of the participants. Conclusions: The live streaming's characterization and the guests for the presentation of the content demonstrate that the informational practices are based on the concept of dissemination of information, which can be identified from the proposed categories. The discussions also point out the need for further analysis in Information Science to expand the interpretations of the investigated object.
\end{abstract}

Keywords: Live streaming; Pandemic; Informational practices; Dissemination of Information; Information Science

\section{INTRODUÇÃO}

O ano de 2020 entrou para a história da humanidade por conta da pandemia de covid-19, forçando a prática do distanciamento social como a melhor forma de prevenção e não propagação da doença. Concomitantemente a isso, o cancelamento de eventos com aglomeração de pessoas impeliu que novos comportamentos em relação ao acesso às informações fossem evidenciados. Foi possível constatar também práticas informacionais pautadas na disseminação de conteúdos falsos (Souza, 2020), tanto no que se referiam a notícias, quanto a assuntos científicos. Outra prática identificada foi a realização de lives em mídias sociais, que já registrava uma escalada ascendente ao longo dos últimos anos e que, nessa conjuntura pandêmica, ganhou proporção ainda maior, viabilizando discussões sobre conteúdos diversos de forma remota. Concernente à socialização de conteúdos na web, as lives disponibilizadas em plataformas digitais têm se consagrado como opção de disseminação de informações.

Tais práticas informacionais denotam o quanto distintos atores sociais estabelecem formas de interlocução com suas audiências, sendo as lives parte das estratégias para a ampliação desses públicos. Além disso, as lives viabilizam relações de lealdade por parte do usuário (Hsu, Lin, \& Miao, 2020), relativas à fidelização aos canais pelos quais as informações são transmitidas ao vivo.

A expressão live caracteriza a transmissão ao vivo através de vídeos em mídias sociais realizada na web. As lives no geral são feitas de forma simples e ágil, através das quais os seguidores da plataforma recebem notificações 
de que elas estão acontecendo naquele momento. A maioria das plataformas de mídias sociais populares como YouTube, Facebook, Twitter, Instagram e TikTok apresentam o recurso para a composição de lives (Reis, 2020).

Especificamente em relação à comunidade de profissionais da área da Ciência da Informação, ações estiveram atreladas à minimização dos impactos da pandemia em públicos vulneráveis economicamente; a reordenação de produtos que permitiram acesso livre a serviços informacionais e a disseminação de informações através de lives. Seguindo nesta linha de intelecção, foi percebido, empiricamente, que o fenômeno também atingiu a área de Ciência da Informação no Brasil. Tal observação pode ser afirmada em razão de que, em diferentes mídias, houve a divulgação de lives que abordaram conteúdo da área a partir do final de março de 2020.

Em relação a esse último aspecto, decorrente de funcionalidades proporcionadas através de plataformas de mídias sociais, as lives passaram a ser usadas de forma abrangente e ostensiva pela comunidade da área com variados propósitos.

Outro aspecto alusivo às lives que deve ser destacado é o fato de que tanto as temáticas, quanto o conteúdo das transmissões ao vivo consagram-se como indícios de interlocuções pautadas por profissionais da Ciência da Informação em meio à pandemia. Cabe inquirir o quanto as lives representam a ampliação de reconhecimento pela comunidade da área, pois a autoridade pode ser compreendida como

[...] medida de influência de um ator com relação a sua rede, juntamente com a percepção dos demais atores da reputação dele". A autoridade compreende também reputação, mas não se resume a ela. "A autoridade é decorrente não apenas do capital social relacional, mas, igualmente, do capital social cognitivo" (Recuero, 2009).

É preciso destacar que o capital cognitivo resulta em popularidade e destaque dos atores sociais na rede. Considerando a recíproca lógica entre ciência e a web, destaca-se que as interlocuções entre indivíduos da comunidade acadêmica têm se redimensionado, bem como imbricam-se às noções de popularidade e autoridade científica (Bourdieu, 1994).

Diante do contexto, compreender as práticas informacionais realizadas por esses atores mostra-se relevante para a reflexão sobre novos comportamentos que possam ser identificados na sociedade diante da diminuição da sociabilidade presencial, que se constitui em um dos aspectos do que está sendo denominado de "novo normal".

A partir do exposto, este trabalho tem como objetivo geral analisar as lives realizadas por integrantes da comunidade da Ciência da Informação em meio à pandemia de covid-19. Considerando os aspectos até aqui elencados, no tópico subsequente serão abordadas as potencialidades das lives, interpretando-as como prática informacional que tem o objetivo de disseminar informações na web. Tal conceito foi assumido como forma de possibilitar que limites conceituais sejam discutidos à luz de contribuições advindas dos estudos desenvolvidos na área.

$\mathrm{Na}$ seção posterior, encontram-se detalhados os aspectos teóricos e conceituais que caracterizam o presente estudo.

\section{AGIR NA URGÊNCIA: LIVES COMO PRÁTICAS INFORMACIONAIS}

Práticas informacionais se constituem como um conceito que sofre clivagens a partir de aspectos culturais, tecnológicos, sociais e jurídicos; potencializando estudos na Ciência da Informação que tenham por parâmetro os aspectos relacionados a essa complexidade de variantes. As diversas possibilidades em relação ao conceito, se consideradas as possibilidades de como práticas informacionais podem ser analisadas, permitem desvelamentos relativos a processos de obtenção, busca, serendipidade, uso, reuso e compartilhamento de informações entre as coletividades. (Araújo, 2017; Marteleto, 1994; McKenzie, 2003; Savolainen, 1995, 2007; Savolainen e Dervin 1997; Harlan, 2012;).

A emergência de um novo conceito, com todas as suas distintas manifestações, vem atestar sobretudo a riqueza e a complexidade do campo do real, um real que sempre se coloca como um desafio para a pesquisa científica. Isso se verifica de forma ainda mais incisiva no campo de estudos de usuários da informação, que lida com objetos que são também sujeitos (os usuários) que utilizam dispositivos em constante mudança (as técnicas e tecnologias informacionais) para lidar com algo de natureza fluida e cambiante (Araújo, 2017, p. 233).

Estudos que analisam as lives têm sido desenvolvidos na Ciência da Informação (Scheibe, Fietkiewicz, e Stock, 2016; Matsumoto, 2019; Vaibhav et al., 2019, identificando práticas informacionais a partir de ênfases em plataformas de games. Relativo aos estudos de práticas informacionais, Savolainen (1995), a partir do modelo ELIS (Everyday Life Information Seeking), propicia uma ampliação na perspectiva dos estudos de usuários, ao considerar elementos subjetivos e condicionantes sociais como fatores que conformam práticas, tendo como norte interpretativo contribuições das ciências humanas e sociais. Corrobora esse panorama Araújo (2017, p. 218-219), sendo categórico ao afirmar que 
a proposta de pesquisa em torno da ideia de "práticas informacionais" tem origem no quadro intelectual das ciências humanas e sociais tomadas como um todo, quadro esse marcado pela existência de distintas escolas ou tradições de pesquisa que se estruturam em torno de determinadas concepções.

Tal origem implica em observar um leque de fenômenos, tendo por referência aspectos centrados no paradigma social da Ciência da Informação. Assumindo-o, o pesquisador ultrapassa a referência às abordagens tradicionais e cognitivas dos estudos de usuários para considerar tensionamentos possíveis entre estrutura, sujeitos e informação. Isso porque há um deslocamento da tríade ação-cognição-sentimento, voltando-se as análises para os condicionamentos, a estrutura, as interações sociais.

Por força de tais alterações, foi adotado o conceito de prática informacional como "[...] mecanismos de apropriação, rejeição, elaboração de significados e valores, não numa sociedade sincrônica, que guarda uma relação direta e cumulativa com a tradição, mas naquela onde os sujeitos elaboram suas representações" (Marteleto, 1994, p. 134). Tal concepção considera que as práticas informacionais congregam em si a possibilidade de discussões acerca do protagonismo dos indivíduos e coletividades na consolidação e reordenação de suas identidades. Outros componentes de constituição desta atmosfera estão relacionados às interações, cooperações e compartilhamento coletivo de conteúdos entre os participantes, redefinindo a racionalidade que tenha por foco o uso de conhecimentos adquiridos das inter-relações sociais.

O uso do conceito de práticas informacionais em investigações recentes não pretende, de forma alguma, suplantar as pesquisas desenvolvidas a partir das perspectivas do "uso" e do "comportamento informacional". Pesquisas mais orientadas por um caráter utilitário e/ou aplicado continuam sendo necessárias. O que se espera com o desenvolvimento de um novo conceito, e do movimento reflexivo que o acompanha, é iluminar determinados aspectos da realidade, determinadas problemáticas, que até então não vinham sendo estudadas (ou suficientemente estudadas) (grifo nosso) (Araújo, 2017, p. 233).

Especificamente neste estudo, partiu-se da premissa de que as lives constituem-se a partir de práticas informacionais de disseminação da informação. O conceito aqui adotado assume que disseminar informação supõe tornar pública a produção de conhecimentos gerados ou organizados por uma instituição. A noção de disseminação da informação é comumente interpretada como equivalente à de difusão, ou mesmo de divulgação (Lara \& Conti, 2003). Embora a autora circunscreva o conceito às instituições, compreende-se que os conhecimentos são produzidos pelos atores sociais, no âmbito dessas instituições ou a partir de práticas cotidianas na web. Tratando-se de profissionais da Ciência da Informação, cabe destacar que os mesmos têm a atribuição de realização de tais processos em suas atividades. Dessa forma, a disseminação naturaliza-se como prática profissional e social; agora transplantada para a web.

No contexto em discussão, a disseminação de informações requer referências éticas em relação a esses processos de comunicação pública da ciência. Nesse sentido e, em meio ao evento pandêmico, se coaduna a disseminação ética da informação. Projetá-la, sob a possibilidade de clivagem de práticas discursivas e ações concretas, requer pensar o outro como referência, em consideração às questões circunscritas a uma dada coletividade.

Peculiaridade e produto da clivagem entre teoria e prática respaldam o conceito de disseminação seletiva de informações (DSI), considerado como um sistema no qual são desenvolvidos práticas e serviços com uma periodicidade estabelecida (C. G. Sousa \& Brighenti, 1981), de acordo com o perfil dos usuários (Mondschein, 1990a, 1990b), tendo como propósito a disponibilização e o compartilhamento de produtos informacionais. Destaca-se que a disseminação seletiva da informação não se caracteriza como um processo apenas vinculado às atividades profissionais, mas, sobretudo, consagra-se como prática social direcionada a públicos especializados.

Disseminação da informação como prática e como conceito, quando atrelados ao qualificador científico, estão relacionados à alternativa de democratizar informações relativas à ciência (Serpa, 2018). A disseminação científica pode ser compreendida como um processo direcionado a especialistas sem que a linguagem especializada necessariamente a caracterize, e tampouco as informações estejam relacionadas a resultados de pesquisas. Tem como característica distintiva da comunicação científica o fato de que o conteúdo das informações veiculadas não se caracteriza pelo crivo de avaliação entre pares, mas pode fazer referência a conteúdos e informações de maneira fracionada, tangencial ou correlacional; utilizando a linguagem adotada pelo campo. Além disso, defende-se que a disseminação também pressupõe uma intencionalidade no que se refere ao universo de pares aos quais são dirigidas as informações. Para R. S. C. Sousa, Bufrem, e do Nascimento (2015, p. 285).

A disseminação científica pressupõe, tal qual a comunicação científica, a intencionalidade no que se refere ao universo de interlocutores aos quais são dirigidas as informações, mas dela se diferencia por não cumprir com algumas prerrogativas para a formalização do conhecimento científico, como, por exemplo, a avaliação pelos pares.

Considerando tais peculiaridades, requer que seja avaliada a possibilidade de compreender quais conceitos alicerçaram os processos de comunicação, identificados nas lives. A metodologia a seguir detalha as decisões tomadas no decorrer do processo exploratório para consecução deste estudo. 


\section{METODOLOGIA}

Pesquisa de natureza aplicada, exploratória-descritiva e de abordagem quali-quantitativa, que analisou as lives realizadas por profissionais da Ciência da Informação no Instagram. Em relação à técnica de coleta de dados, o estudo pautou-se pela observação assistemática na web e, posteriormente, pela análise de conteúdo (Bardin, 2011). Por tratar-se de abordagem qualitativa, a intencionalidade em relação aos aspectos analisados emergiram do processo, quais sejam: relatar a dinâmica das lives, categorizar os assuntos de acordo com os títulos das lives, caracterizar os responsáveis pelo conteúdo das transmissões e compreender quais processos do ponto de vista conceitual preponderam entre as lives realizadas.

O percurso metodológico teve seu início em 30 de abril de 2020 a partir de uma busca no Google com a expressão de busca "lives em tempos de pandemia". Considerando os resultados obtidos, identificou-se a ocorrência de transmissões abordando conteúdos variados e promovidas por instituições de distintas naturezas administrativas.

Posteriormente foi realizada a escolha da plataforma digital Instagram, na qual ocorreram lives sobre conteúdos inerentes à Ciência da Informação. Tal escolha ocorreu em razão de que estudos precedentes da atualidade a mencionam como a rede social com maior percentual (47\%) relativo à preferência entre os brasileiros (Costa, 2019).

Os critérios para escolha dos perfis do Instagram tiveram como base a divulgação de imagens com informações sobre as lives, compartilhadas em diferentes mídias. Foram selecionados aleatoriamente cinco perfis que estavam realizando as transmissões na plataforma Instagram. Foram descartados da seleção os perfis que fizeram divulgação no Instagram, mas fizeram uso de outras plataformas para a realizar as transmissões ao vivo. Posteriormente, chegou-se ao número de três perfis e, após verificar que um deles havia feito poucas lives, consideraram-se apenas dois que estavam realizando transmissões com frequências diárias, permitindo a composição de um corpus quantitativamente mais amplo.

Os perfis escolhidos foram o @biblioforadacaixa e o @webconcib; o primeiro era um perfil já existente há um ano antes da pandemia e o segundo foi criado no início da necessidade de distanciamento social no país. Ambos os perfis foram idealizados por coletivos de profissionais e estudantes da área de Ciência da Informação e manifestaram que a prática de lives se constituem em alternativa para manter o diálogo com a comunidade da área, em meio às condições impostas pela pandemia.

A coleta de dados foi realizada no período compreendido entre 06 a 12 de maio de 2020, primeiramente através do acesso aos perfis selecionados. Posteriormente foi realizada a leitura flutuante (Bardin, 2011) das postagens que divulgavam as lives e as mensagens realizadas pela audiência. A partir do corpus de dados obtidos, foram propostas inicialmente 12 categorias. Dessas, uma delas foi renomeada para Aspectos Gerais da Informação, com a finalidade de englobar temas uma quantidade pouco expressiva de ocorrências, demandando que uma segunda categoria fosse incorporada à mais abrangente, resultando em 11 categorias.

Em um terceiro momento, dados referentes à dinâmica das lives foram coletados dos vídeos disponibilizados posteriormente no Youtube, que foi a plataforma escolhida pelos idealizadores dos perfis para armazenar o conteúdo das transmissões. Na sequência, houve a transcrição dos dados que foram julgados relevantes para o estudo em uma planilha do Excel.

Diante disso, são apresentadas no Quadro 1 as definições das categorias obtidas das análises dos títulos, explicitadas com o intuito de detalhar quais os critérios utilizados para as interpretações. 


\begin{tabular}{|c|l|}
\hline Categorias & Critérios para interpretação dos dados \\
\hline Acessibilidade & $\begin{array}{l}\text { Abordam soluções de informação para pessoas com necessidades } \\
\text { especiais }\end{array}$ \\
\hline Formação acadêmica & Elencam experiências formativas discentes e docentes \\
\hline Guerras informacionais & $\begin{array}{l}\text { Apresentam discussões sobre fake news, pós-verdade, fake science e } \\
\text { outros aspectos referentes a conflitos que tenham a informação como } \\
\text { cerne }\end{array}$ \\
\hline Questões de gênero & Abordam o gênero em diferentes perspectivas na área da informação \\
\hline Questões raciais & $\begin{array}{l}\text { Apresentam discussões raciais como sendo o aspecto principal na área } \\
\text { da informação e na literatura }\end{array}$ \\
\hline Competência em informação & $\begin{array}{l}\text { Destacam a competência da informação como alternativa para } \\
\text { minimizar problemáticas em diferentes contextos }\end{array}$ \\
\hline Questões sociais & $\begin{array}{l}\text { Abordam aspectos relativos a problemas sociais que não foram } \\
\text { categorizados em questões de gênero e raça }\end{array}$ \\
\hline Livro, Leitura, Letramento & $\begin{array}{l}\text { Consideram aspectos políticos, culturais e sociais relacionados ao } \\
\text { livro, leitura, letramento profissional }\end{array}$ \\
\hline Aspectos gerais da \\
informação & $\begin{array}{l}\text { Apresentam assuntos relacionados a experiência, ao profissionalismo, } \\
\text { ao protagonismo e ao empreendedorismo do profissional da } \\
\text { informação }\end{array}$ \\
\hline $\begin{array}{l}\text { Contemplam assuntos que não se encontram entre as categorias anteriores } \\
\text { e que sejam relacionados a questões técnicas ou } \\
\text { de tecnologia }\end{array}$ \\
\hline
\end{tabular}

Quadro 1. Categorias e critérios para interpretação dos dados.

Fonte: dados da pesquisa (2020)

No espaço de escrita a seguir são apresentados os dados, considerando o processo exploratório-descritivo empreendido.

\section{DESCRIÇÃO E ANÁLISE DOS DADOS}

Como forma de apresentação, descrição e análise dos dados, nesta seção são apresentadas questões relativas às lives realizadas pelos perfis selecionados.

Durante o período de coleta de dados nos dois perfis analisados, foram realizadas 74 lives. O perfil @webconcib contabilizou 36 lives, entre o dia da primeira transmissão (05/04/2020) até o último dia da coleta de dados (12/05/2020) e conquistou uma audiência de 2.348 seguidores. No perfil @biblioforadacaixa foram observadas 38 lives, entre a primeira transmissão (04/04/2020) e o último dia da coleta de dados (12/05/2020), e neste período, incrementou a sua audiência, totalizando 1.538 seguidores.

Com relação à dinâmica de realização das transmissões ao vivo, ambos os perfis adotaram uma prática semelhante, baseada na informalidade, através de uma linguagem coloquial, em relação à apresentação e à interlocução entre os atores das lives: convidado, mediador e audiência.

Entretanto, no que concerne ao conteúdo das lives, foi identificada uma quantidade expressiva de termos técnicos da área da Ciência da Informação, o que permite afirmar que a tradução da linguagem não se caracterizou como cerne da recomposição dos conteúdos. Dessa forma, a possibilidade de que os processos de comunicação tivessem por objetivo atingir exclusivamente a comunidade da Ciência da Informação foi evidenciada, pois tanto os assuntos, quanto termos e expressões utilizadas não se caracterizaram através de processos de divulgação científica, que tem por ênfase a recomposição discursiva como forma de entendimento em relação ao conteúdo por audiências leigas (R. S. C. Sousa et al., 2015).

As transmissões tiveram duração média de 60 minutos, perspectiva evidenciada em estudo precedente de Scheibe et al. (2016) ainda que este limite de tempo seja determinado pela plataforma e exista a possibilidade da live ser encerrada anteriormente. Nos dois perfis, as lives foram mediadas por, pelo menos, um dos idealizadores do perfil e a transmissão iniciava com a apresentação do convidado pelo mediador. O convidado deveria discorrer sobre o tema da live por cerca de 30 minutos; após este período, o mediador fazia perguntas da audiência, algumas previamente enviadas e outras realizadas durante a transmissão. As mediações das lives foram realizadas de forma alternada por integrantes da equipe idealizadora dos canais, demonstrando a adoção de uma sistemática pautada no trabalho coletivo.

Concernente ao acesso ao conteúdo das lives, os perfis do Instagram disponibilizaram os vídeos no Youtube, motivados por pedidos da audiência via mensagens nas postagens, que manifestaram não ter conseguido assistir o conteúdo de forma síncrona à transmissão. Ainda que não tenha sido identificada a razão da escolha da plataforma Youtube para a posterior disponibilização dos vídeos, depreende-se que tenha sido escolhida em razão 
de o Youtube ser uma das fontes de informação mais populares entre os brasileiros, perfazendo um total de $49 \%$ entre a população e 55\% entre os jovens (Câmara dos Deputados, 2019). Além disso, constatou-se que, no início da pandemia, a plataforma Instagram tinha limitações relativas ao armazenamento do conteúdo de vídeos. Somente algum tempo transcorrido de distanciamento social, novas funcionalidades foram incorporadas à plataforma, viabilizando que as lives pudessem ser disponibilizadas diretamente no IGTV (A. Rocha, 2020).

No que diz respeito aos temas abordados nas lives, evidenciou-se através do Quadro 2 uma diversidade de assuntos correlatos ao campo de estudo da Ciência da Informação, que foram extraídos dos títulos das lives, anunciados nas postagens que fizeram a divulgação das 74 transmissões, contabilizadas durante o período que compreendeu esse estudo. Levando em consideração essa quantidade, foi efetivada a categorização das temáticas, conforme Quadro 1, apresentado anteriormente na metodologia deste estudo.

\begin{tabular}{|c|c|}
\hline Categorias & Temas \\
\hline Acessibilidade & Surdez. Deficiência visual. Repositórios digitais (surdos) \\
\hline Formação acadêmica & Estudar fora do país. Experiências formativas. Formação de \\
professores
\end{tabular}

Quadro 2. Categorização dos temas das 74 lives abordadas nos dois perfis analisados. Fonte: dados da pesquisa (2020)

Conforme o Quadro 2, a diversidade de temas tratados nas 74 lives indica o quanto as transmissões se constituíram em subprodutos de comunicação pública da ciência, produzidos de forma ostensiva pela comunidade da Ciência da Informação, de acordo com uma prática informacional sui generis. Nesta mesma linha, E. C. F. Rocha, Gandra, e Rocha (2017, p. 96) entendem as práticas informacionais como sendo

aquelas que vão além do estudo do comportamento informacional, mas que procuram escrutinar atividades relacionadas ao contato socialmente mediado com a informação (incluindo atividades comunicativas) e as práticas predominantemente relacionadas à informação em ambientes escolares, de pesquisa e do cotidiano, seja físico ou digital.

Relativo às lives, tal constatação pode ser assumida em razão da média de duas ocorrências por dia e 12 por semana, expressando que a comunidade incorporou tal prática informacional ao seu cotidiano. 


\begin{tabular}{|c|c|c|c|}
\hline Categorias & @webconcib & @biblioforadacaixa & $\begin{array}{c}\text { Ocorrências nas 74 lives } \\
\text { por categoria }\end{array}$ \\
\hline Acessibilidade & 0 & 3 & 3 \\
\hline Formação acadêmica & 0 & 3 & 3 \\
\hline Guerras informacionais & 3 & 0 & 3 \\
\hline Questões de gênero & 3 & 0 & 3 \\
\hline Questões raciais & 2 & 1 & 4 \\
\hline $\begin{array}{c}\text { Competência em } \\
\text { informação }\end{array}$ & 4 & 0 & 4 \\
\hline Questões sociais & 3 & 1 & 13 \\
\hline $\begin{array}{c}\text { Livro, Leitura, } \\
\text { Letramento }\end{array}$ & 4 & 9 & 19 \\
\hline Atuação profisional & 5 & 14 & 19 \\
\hline $\begin{array}{c}\text { Aspectos gerais da } \\
\text { informação }\end{array}$ & 12 & 7 & \\
\hline
\end{tabular}

Quadro 3. Ocorrências de lives por categoria temática e perfil. Fonte: dados da pesquisa (2020)

Num primeiro momento, foi possível observar a prevalência de processos de disseminação da informação, distribuídos em duas categorias do estudo em igual proporção. A primeira das categorias é pertinente à atuação profissional condizente com as atividades dos bibliotecários 19 (25,67\%), na qual foi possível identificar questões como engajamento político dos bibliotecários e temáticas de caráter utilitário, como os concursos públicos. Na segunda relacionada a aspectos gerais 19 (25,67\%), destaca-se a temática das Humanidades Digitais.

É relevante notar que essas abordagens de temáticas se encontram como propostas de consolidação em voga no âmbito da Ciência da Informação no Brasil, abordando tópicos de estudos emergentes na área, como as questões relacionadas a gênero, à raça e às guerras informacionais, totalizando 10 (13,51\%) ocorrências em relação ao total de lives.

Os dados arrolados no Quadro 4 demonstram que a pandemia está elencada como elemento tangencial à discussão, não se configurando como foco temático das lives. Essa análise encontra-se balizada no número diminuto de lives que fizeram relação com a pandemia dentre os temas propostos, totalizando 11 (14,86\%) menções, num total de 74 lives, levando em consideração que ambos os perfis ressaltaram o isolamento social e a pandemia como motivação para a proposição de realização de lives em seus canais.

\begin{tabular}{|c|c|}
\hline Categorias & Títulos \\
\hline \multirow{3}{*}{ Atuação profissional } & Os arquivos e arquivologia: aspectos sociais e técnicos em tempos de pandemia \\
\hline & Coleções especiais em bibliotecas acadêmicas dos EUA em tempos de pandemia \\
\hline & Protagonismo profissional como será o novo normal? \\
\hline $\begin{array}{l}\text { Competência em } \\
\text { informação }\end{array}$ & $\begin{array}{l}\text { Competência em informação para a área da saúde: reflexões em tempos de } \\
\text { pandemia }\end{array}$ \\
\hline Guerras informacionais & Guerras informacionais: no contexto da pandemia COVID-19 \\
\hline \multirow{3}{*}{$\begin{array}{l}\text { Aspectos gerais da } \\
\text { informação }\end{array}$} & $\begin{array}{l}\text { As bibliotecas (contemporâneas ou mais do mesmo?) diante da pandemia de } \\
\text { COVID-19 }\end{array}$ \\
\hline & Comunicação científica: como contribuir para vencer a crise? \\
\hline & A ciência da informação, as humanidades digitais e a pandemia \\
\hline $\begin{array}{l}\text { Livro, Leitura, } \\
\text { Letramento }\end{array}$ & Mediação da leitura em período de pandemia \\
\hline \multirow[t]{2}{*}{ Questões sociais } & $\begin{array}{l}\text { Responsabilidade social e Biblioteconomia e Ciências da Informação em } \\
\text { tempos inseguros }\end{array}$ \\
\hline & Comunidades vulnerables en relación a la información sobre el COVID 19 \\
\hline
\end{tabular}

Quadro 4. Categorias das lives e títulos que fizeram relação com o contexto da pandemia. Fonte: dados da pesquisa (2020)

Outra indagação provocada pela interpretação dos dados é que, em meio à urgência demandada pelo cenário pandêmico, seria esperado um protagonismo maior da comunidade da Ciência da Informação em relação à proposição de conteúdo envolvendo as guerras informacionais, visto que os profissionais da área da informação têm, aprioristicamente, a competência para o combate às notícias falsas e seus correlatos: pós-verdade, desinformação, fake news, fakescience, entre outros. Isso porque a desinformação se consolidou como uma prática informacional de proporções não imaginadas em meio à pandemia.

No entanto, verificou-se apenas uma live, dentre as 11, que evidencia a relação dos dois temas (pandemia e notícias 
falsas) no seu título, o que indica a possibilidade de a comunidade da área estabelecer práticas informacionais relativas à desconstrução de informações não confiáveis.

Em relação às características dos convidados, identificados a partir das 74 lives, 28 (37,83\%) têm vínculo de docente em instituições de ensino superior e $46(62,16 \%)$ são profissionais da área da Ciência da Informação. O vínculo acadêmico foi evidenciado no perfil @webconcib, que convidou $23(63,88 \%)$ docentes, no total de 36 . No @biblioforadacaixa, a predominância foi por convidados que estão atuando de forma técnica na área 33 (86,84\%), no total de 38. Estes dados confirmam que as características dos convidados estão alinhadas aos propósitos dos perfis propositores das lives.

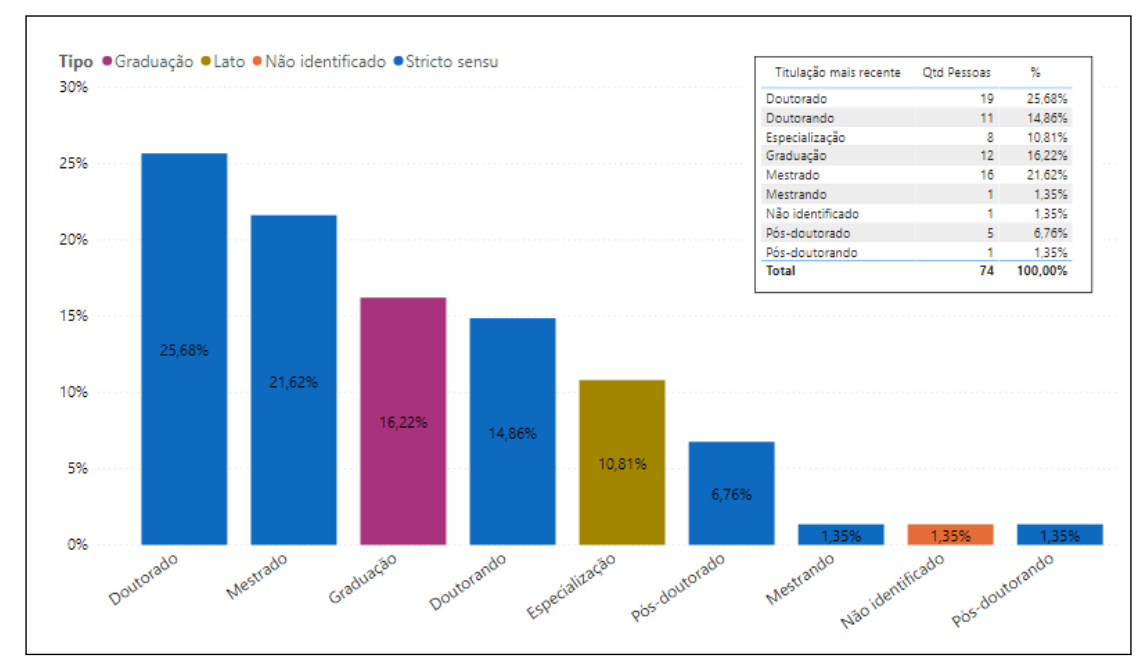

Figura 1. Titulação mais recente dos convidados das lives Fonte: Dados da pesquisa (2020)

Desses, $53(71,62 \%)$ possuem titulação stricto sensu, com predominância de 19 (25,68\%) de doutores, seguido de $16(21,62 \%)$ de mestres. Esses dados demonstraram que a autoridade científica foi um aspecto preponderante relativo às escolhas dos convidados, servindo como atributo de qualidade para proposição das transmissões ao vivo. Ao discutir aspectos relativos à autoridade científica, Bourdieu a definiu

[...] como capacidade técnica e poder social; ou, se quisermos, o monopólio da competência científica, compreendida enquanto capacidade de falar e de agir legitimamente (isto é, de maneira autorizada e com autoridade), que é socialmente outorgada a um agente determinado. (Bourdieu, 1994, p. $122-123)$

Cabe mencionar que houve uma ampla variação geográfica em relação aos convidados responsáveis pela disseminação do conteúdo das lives. Os convidados são provenientes de diferentes regiões do Brasil, conforme pode ser identificado no figura 2.

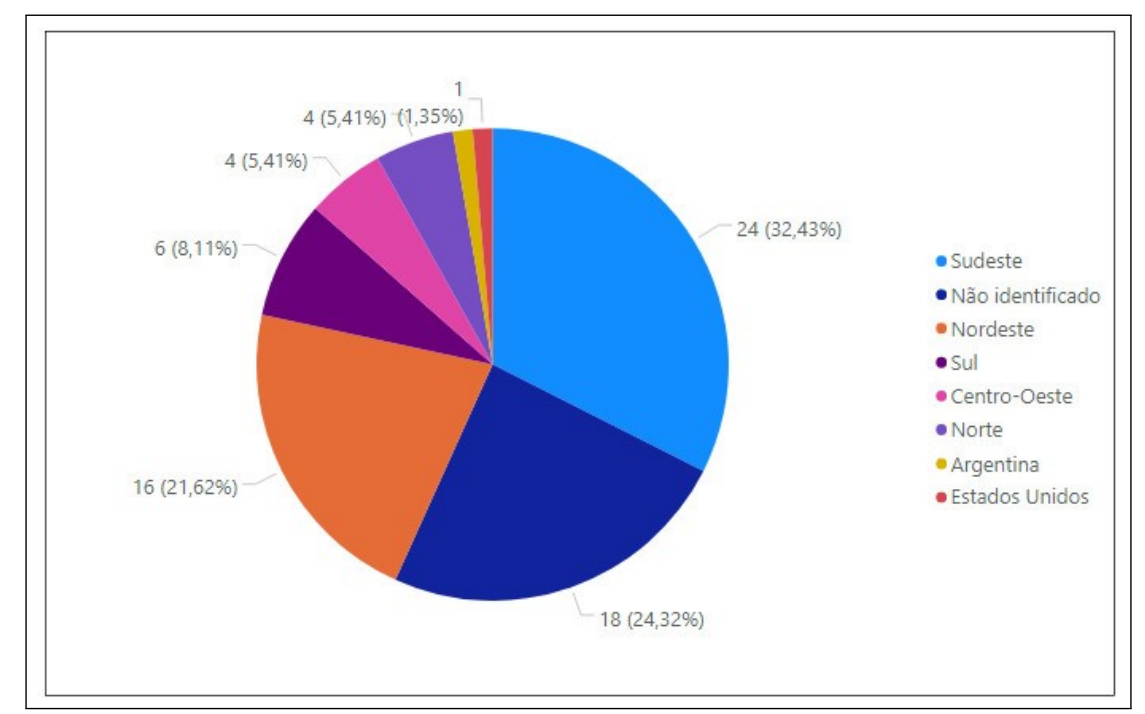

Figura 2. Proveniência geográfica dos convidados

Fonte: dados da pesquisa (2020)

Embora não tenha sido possível conseguir informações sobre a proveniência de 18 (24,32\%) dos convidados, 
ressalta-se a concentração de convidados relativa às regiões sudeste e nordeste que totalizam 40 (54,03\%). Outro destaque está relacionado a apenas duas (2,70\%) participações internacionais, uma da Argentina e outra dos Estados Unidos, o que corrobora que os idealizadores propuseram ações que ultrapassaram a perspectiva de que as falas fossem realizadas por atores sociais que estivessem no país ou de naturalidade brasileira.

\section{CONSIDERAÇÕES FINAIS}

As lives realizadas por profissionais da Ciência da Informação se constituíram em práticas informacionais de significativa relevância em meio à pandemia. Decorrente de tal constatação, assumiu-se que os processos de comunicação estavam fundamentalmente alicerçados no conceito de disseminação da informação. Considerando essa premissa, foi proposta uma aproximação conceitual entre as práticas informacionais e a disseminação da informação.

Neste estudo, nosso propósito foi de analisar aspectos relacionados às lives, nos quais essas práticas tiveram maior relevância no período compreendido entre 30 de abril de 2020 a 12 de maio de 2020, emergidos do processo exploratório-descritivo.

A linha de intelecção que se buscou defender assumiu que as lives constituem-se em práticas informacionais em meio à pandemia, não se propondo a atingir o público leigo. No entanto, inflexões e retornos reiterados ao fenômeno mostraram que essas práticas sociais estiveram preponderantemente relacionadas a partir do direcionamento das informações à própria comunidade da Ciência da Informação.

Alusivo ao percurso metodológico adotado, caracterizou-se como híbrido em níveis metodológico e procedimental, considerada sua abordagem exploratória-descritiva, mista (quali-quantitativa) e tendo como procedimento a observação assistemática na web e a análise de conteúdo.

Considerados os propósitos dos perfis analisados, a descrição da dinâmica das lives permitem dizer que as transmissões se caracterizaram fundamentalmente em confirmar as intenções de prática informacional idealizada, quanto ao agir na urgência e de manter canal de comunicação entre profissionais da área da informação, mesmo em meio à situação adversa imposta pela pandemia.

As análises permitiram inferir que a suplementaridade entre assuntos e temáticas abordadas nas lives, considerando o privilégio a questões profissionais e acadêmicas, bem como as características dos produtores e convidados das lives, demonstram que as práticas informacionais pautaram-se no conceito de disseminação de informações o que pode ser identificado a partir das categorias propostas. Ainda assim, cabe destaque ao fato de que foi possível identificar a ampliação das audiências e a dispersão geográfica em relação à origem dos participantes.

Os profissionais da Ciência da Informação necessitam desvincularem-se da perspectiva de autonomia das atividades técnico-científicas, deixando de pressupor que seja suficiente que sua contribuição reverbere fundamentalmente no âmbito da sua comunidade. Em razão disso, seria importante avaliar, através de estudos complementares, a razão da inserção pouco incisiva dos profissionais da Ciência da Informação como protagonistas nestes processos; através de ações que auxiliem no enfrentamento às consequências da pandemia. Considera-se o uso da informação e o enfrentamento à desinformação como estratégias efetivas de combate ao cenário pandêmico. Requer pensar as implicações dos processos de comunicação em diferentes instâncias sociais, ou seja, concebê-las como atividade política não apenas na dimensão subjetiva, mas também em níveis micro, meso e macro institucionais, articulando ações a movimentos originários da sociedade nesses tempos de incertezas.

As discussões levantadas neste estudo também apontam para a necessidade de que análises posteriores na Ciência da Informação possam ampliar interpretações acerca do objeto investigado, tendo por referência aspectos teóricos e metodológicos ainda não contemplados. Essa proposta está em aberto e à espera de engajamento coletivo. 


\section{REFERÊNCIAS}

Araújo, C. A. Á. (2017). O que são práticas informacionais? Revista Informação em Pauta, 2(esp), 217-236. Recuperado de http://www.periodicos.ufc.br/informacaoempauta/ article/view/20655

Bardin, L. (2011). análise de conteúdo. São Paulo: Edições 70.

Bourdieu, P. (1994). O campo científico. In Pierre bourdieu. São Paulo: Ática.

Câmara dos Deputados. (2019). Câmara e senado divulgam pesquisa sobre redes sociais e fake news. Brasília: Câmara dos Deputados. Recuperado de https://www.camara.leg.br/ assessoria-de-imprensa/623705-camara-e-senado-divulgam -pesquisa-sobre-redes-sociais-e-fake-news

Costa, T. (2019). Quais são as redes sociais mais usadas no brasil em 2019? Recuperado de https://rockcontent.com/ blog/redes-sociais-mais-usadas-no-brasil

Harlan, M. A. (2012). Information practices of teen content creators: the intersection of action and experiences (Tese de Doutorado, School of Information Systems, Science and Engineering Faculty, Queensland University of Technology). Recuperado de https://eprints.qut.edu.au/57125/1/Mary _Harlan_Thesis.pdf

Hsu, C. L., Lin, J. C. C., \& Miao, Y. F. (2020). Why are people loyal to live stream channels? the perspectives of uses and gratifications and media richness theories. Cyberpsychology, Behavior, and Social Networking, 23(5), 351-356. doi: 10.1089/cyber.2019.0547

Lara, M. L. G. d., \& Conti, V. L. (2003). Disseminação da informação e usuários. São Paulo em perspectiva, 17(34), 26-34. Recuperado de https://www.scielo.br/pdf/spp/ v17n3-4/a04v1734.pdf

Marteleto, R. M. (1994). Cultura da modernidade: discursos e práticas informacionais. Revista da Escola de Biblioteconomia da UFMG, Belo Horizonte, 23(2). Recuperado de http://hdl.handle.net/20.500.11959/brapci/74904

Matsumoto, G. H. P. (2019). Fatores de sucesso para canais de live streaming de jogos online na percepção dos usuários brasileiros da twitch.tv (Trabalho de Conclusão de Curso, Faculdade de Administração e Ciências Contábeis, Universidade Federal do Rio de Janeiro, Rio de Janeiro, RJ, Brasil). Recuperado de http://hdl.handle.net/11422/12109

McKenzie, P. J. (2003). A model of information practices in accounts of everyday-life information seeking. Journal of documentation, 59(1), 19-40.

Mondschein, L. G. (1990a). Sdi use and productivity in the corporate research environment. Bibliotecas Especiais, $81(4), 265-79$.

Mondschein, L. G. (1990b). Selective dissemination of information (sdi): Relationship to productivity in the corporate r\&d environment. Journal of documentation, 46(2), $137-45$.

Recuero, C., R. (2009). Redes sociais na internet (2a. ed., v. rev. e ampl). Porto Alegre: Sulina.

Reis, E. (2020). O que é uma live? saiba tudo sobre as transmissões ao vivo na internet. Techtudo. Recuperado de https://www.techtudo.com.br/noticias/2020/03/ o-que-e-uma-live-saiba-tudo-sobre-as-transmissoes-ao-vivo -na-internet.ghtml

Rocha, A. (2020). Instagram testa recurso para salvar lives no igtv após 24h. Recuperado de https://canaltech.com.br/redes-sociais/instagram-testa -recurso-para-salvar-lives-no-igtv-apos-24h-163577

Rocha, E. C. F., Gandra, T. K., \& Rocha, J. A. P. (2017). Práticas informacionais: nova abordagem para os estudos de usuários da informação. Biblios(68), 96-109. doi: https://dx.doi.org/10.5195/biblios.2017.445

Savolainen, R. (1995). Everyday life information seeking: Approaching information seeking in the context of "way of life". Library and information science research, 17(3), 259-294.

Savolainen, R. (2007). Information behavior and information practice: reviewing the "umbrella concepts" of informationseeking studies. The library quarterly, 77(2), 109-132.

Savolainen, R., \& Dervin, B. (1997). Information seeking in context. Londres: Taylor Graham.

Scheibe, K., Fietkiewicz, K. J., \& Stock, W. G. (2016). Information behavior on social live streaming services. Journal of Information Science Theory and Practice, 4(2), 6-20. Recuperado de https://doi.org/10.1633/JISTAP.2016.4.2.1

Serpa, S. (2018). Quality and democraticity in scientific dissemination. Sociology International Journal, 5(2), 429. doi: 10.15406/sij.2018.02.00080

Sousa, C. G., \& Brighenti, N. C. (1981). Disseminação seletiva da informação: um serviço de referência. Boletim $A B D F, 4(1), 28-37$.

Sousa, R. S. C., Bufrem, L. S., \& do Nascimento, B. S. (2015). Olhares complementares sobre letramento científico e o papel dos pesquisadores em comunidades virtuais. Em Questão, 21(3), 271-295. Recuperado de 10.19132/1808 $-5245213.271-295$

Souza, N. I. S. (2020). A disseminação de fake news no caso do coronavírus (covid-19): uma análise discursiva. Revista Memento, 1(1), 3-20. Recuperado de http://periodicos.unincor.br/index.php/memento/ article/view/6123/pdf_174

Vaibhav, D., Abigail, R., Ferchaud, A., Seibert, J., Weinbrecht, V., \& Sellers, N. (2019). Don't just watch, join in: Exploring information behavior and copresence on twitch. Computers in Human Behavior. doi: 10.1016/j.chb.2019.106221

Valerim, P. \& Souza, R. S. C. (2020). Live streaming em tempos pandêmicos: práticas informacionais realizadas por profissionais da Ciência da Informação. AtoZ: novas práticas em informação e conhecimento, 9(2), 173 - 182. Recuperado de: http://dx.doi.org/10.5380/ atoz.v9i2.75755 